\title{
THE INFLUENCE OF CRITICAL FACTORS ON THE BEHAVIOR INTENTION TO COMPUTERIZED ACCOUNTING SYSTEMS (CAS) IN CEMENT MANUFACTURES IN LIBYA
}

\author{
Omran Abdullah Naheb, Eko Ganis Sukoharsono, and Zaki \\ Baridwan \\ Accounting Department,Faculty of Economics and Business, University of \\ Brawijaya,Indonesia
}

\begin{abstract}
Due to the rapid change in technology, businesses prefer to track monetary transactions using computerized system and the advancements in information technology have eventually led to the introduction of Computerized Accounting Systems (CAS) to help produce relevant, trusted, and representative financial reports for both management and external users for decision-making without errors. The shifting from conventional accounting system in Libyan organizations to Computerized Accounting Systems (CAS) resulted in some company's staff's resistance on the adoption of the new technologies. Therefore, this study aims to examine the Influence of Critical Factors on the Behavior Intention to Computerized Accounting Systems (CAS) In Cement Manufactures In Libya which are, Performance Expectancy, Effort Expectancy, Facilitating Conditions, Self-efficacy and Tasktechnology fit (TTF) to accountant Behavioral Intentions (ABI) of using (CAS) in Libyans cements organizations. This study utilized quantitative research method and survey questionnaires distributed 240 forms to employee of in accounting and finance department in four biggest Libyan cement manufacturers, Al- Murgab, Lubda, Souk Al khamis and Zalitan. The 189 returned forms were analyzed using PLS software. The result of analysis hypothesis revealed that there is a significant effect among all variables to Behavioral Intentions, but, only, Effort Expectancy does not have impacts on the Behavior Intention to Computerized Accounting Systems (CAS) In Cement Manufactures In Libya.

Keywords: Critical Factors, Behavior Intention, Computerized Accounting Systems (CAS), Libyan cement manufacturers
\end{abstract}

\section{INTRODUCTION}

Nowadays, business environment is very aggressive and technology role in business sector has gotten to be a crucial wellspring of supportable upper hand and a key weapon for organizations. The ability to harness the technologies to improve the efficiency organizations operations is very important. Over the last decade, the accounting book keeping was done through traditional way and recently due to the revolution in technology the booking has been done through computerized accounting systems (CAS). The aim of book keeping through computerized accounting system is to hold better records, efficient book management, to avoid type errors and ultimately improving the management of their business. The CAS efficiency can be measured through its low cost and easy use. On the other hand, there are very few problems to improve record keeping practices. 
The successful implementation of the (CAS) depends on its actual adoption by accountants within organizations. As a consequence, organizations are increasingly seeking ways to ensure (CAS) that will be adopted by accountants, rather than only focusing on decision makers' decisions to adopt the system (Caglio, 2003, Dowling 2009). Although accountants' involvement played an important role in the successful implementation of the (CAS). Existing researches have mainly focused on issues related to the design, development and performance effects of (CAS) such as by Grabski et al. (2011) and Vaassen \& Hunton (2009). Prior research has shown that the successful adoption of new technology by endusers is mainly determined by their behavioral intention based on Davis et al. (1989), \& Venkatesh et al. (2003). Past studies have emphasized on the importance of individual, technological, organizational and institutional aspects in influencing or forming, to varying degrees, the behavioral intention of end-users (Lee et. Al, 2003), (Oliveira \& Martins, 2011). According to these aspects, end-users develop intention that reflects their true beliefs and perceptions of the new technology, and will subsequently react positively or negatively to adopting or technology, Accordingly, in order to benefit from introduced CAS, it is not enough to simply deploy the AIS and make it available for use (Aoun et al.,2010; Pulakanam \& Suraweera, 2010). Attaining a complete understanding of the factors that will form or affect accountants' behavior towards adopting the AIS is thus a prerequisite to reduce the risk of the system not being adopted by Aoun et al.(2010), \& Caglio (2003).

The examination of factors related to behavioral intention of end-users towards IT adoption has resulted in the emergence of several adoption theories and models. A number of researchers recommend that integrating factors from different theoretical perspectives can provide a holistic understanding of the potential influential factors of IT adoption (Cheng et al., 2009, Oliveira \& Martins, 2011, Venkatesh et al., 2003). Furthermore, according to Breen et al (2003), Gonzalez et al (2012), Oliveira and Martins (2011), to better understand accountant's adoption of the CAS, a range of adoption factors related to individual, technological, organizational and institutional aspects need to be considered yet, the existing literature reveals limited research involving a broader perspective that considers multifaceted factors. While the two prominent IS/IT adoption theories like the unified theory of acceptance and use of technology (UTAUT) based to Venkatesh et al. (2003) Task- technology fit (TTF) model Goodhue and Thompson (1995) has been used independently in prior studies to examine the adoption of various IT applications. Few studies have applied these theories together to examine the behavioral intention of individuals within organizations. Therefore, this study fills the existing research gap by considering individual, technological, and organizational employs UTAUT, TTF in investigating the factors that influences (CAS) adoption by accountants which are: Performance expectancy, Effort expectancy, Facilitating conditions, Self-efficacy and Task- technology fit (TTF). The many advantages from the use of Technology have led many to conclude that Computerized Accounting Systems (CAS) in Corporate Reporting is the 'engine of growth' in business organizations (Frenzel, 2006). It is worth noting that, notwithstanding the introduction of these Computerized Accounting Systems and despite the enormous benefits from the use of these systems, the problem is that in cement manufacture in Libya still make use of the Manual Accounting Systems which are often characterized by keeping a large number of books and are usually associated with errors in recording large volumes of transactions. The conventional accounting system is still in use in Libyan cement companies and very scarce use computer system in accounting and finance in main department and not in sub-unit. There is long process in every accounting operation and in every accounting recordings and treatment. However company's staffs are still resisting to new technologies. Libyan organizations needs to be cost effective and timely in their accounting 
practices which could not be achieved using its traditional way of accounting reporting. CAS is meant to conduct the company's operations and activities, and providing information concerning the variety of users' interest. Hence the main problem arising is the use of traditional accounting system in Libyans organizations, particularly in manufacturing sector. The current study aims to examine critical success factors which are Performance Expectancy, Effort Expectancy, Facilitating Conditions, Self-efficacy and Task-technology fit (TTF) to accountant Behavioral Intentions (ABI) of using (CAS) aspects on accounting practices in Libyans cements organizations, more expiation of these variables presented in chapter two and three in this study. The questions of this study are as follows:

1. Is there any positive impact of Performance Expectancy on Behavior intention of Accountants?

2. Is there any positive impact of Effort Expectancy on Behavior intention of Accountants?

3. Is there any positive impact of Task-technology fit on Behavior intention of Accountants?

4. Is there any positive impact of Facilitating Conditions on Behavior intention of Accountants?

5. Is there any positive impact of Self Efficacy on Behavior intention of Accountants? thus, the critical success factors that could enhance examine The primary objective of the study is to the behavior intention of using Computerized Accounting Systems (CAS), and aspects of accounting practices in Libyans organizations. The general objectives of the research are:

1. To test and analyze an impact of Performance Expectancy on Behavior intention of Accountants.

2. To test and analyze an impact of Effort Expectancy on Behavior intention of Accountants.

3. To test and analyze an impact of Task-technology fit on Behavior intention of Accountants.

4. To test and analyze an impact of Facilitating Conditions on Behavior intention of Accountants.

5. To test and analyze an impact of Self Efficacy on Behavior intention of Accountants.

\section{EMPIRICAL RESEARCH REVIEW}

\section{Unified Theory of Acceptance and Use of Technology (UTAUT)}

Models for technology acceptance and adoption including the technology acceptance model (TAM) based on Davis (1989), theory of reasoned action (TRA) Fishbein \& Ajzen (1975), and innovation diffusion theory (IDT) by Rogers (1995) have been established and tested extensively. More recently, through reviewing and empirically testing the technology acceptance models, Venkatash et al. (2003) proposed a unified model integrating acceptance determinants across several competing models. Referring to the UTAUT, Venkatash et al.'s model has been validated in empirical settings as having superior explanation power over past models.

According to the UTAUT, intention to use the information technology (IT) can be determined by three antecedents: performance expectancy, effort expectancy and social influence and, as a consequence, intention to use is to exert influence on actual behavior toward IT adoption with facilitating conditions by Venkatesh et al. (2003). Specifically, performance expectancy amount how much people recognize a system, such as the Internet or mobile technology, is useful in achieving their goals in terms of job performance. The concept of performance expectancy including perceived usefulness has been considered the most influential tool for explaining the intention to use the system regardless of the types of IT environments, be it mandatory or voluntarily. Hence, UTAUT has integrated models of technology acceptance into the Unified Theory of Acceptance. UTAUT represents 
41 The Influence of the critical factors on the behaviour.......

a significant step forward in the technology acceptance literature, and it suggests core constructs to explain and predict user acceptance of a new technology and aims to explain user intentions to use system and subsequent usage behavior. This theory assess whether the user will be able to accept the new technologies and user's ability to deal with it. The Technology Acceptance Model helps managers, employee and decision makers to assess the success of the introduction of technology to the organization, and motivate users to accept the systems.

The second predictor which has been widely employed throughout technology adoption researches is effort expectancy, which explains how people believe comfortable and find it easy to adopt and employ the system for their jobs. As far as the past experience in the Chinese mobile communication market, thus Park, (2003) \& Yan (2003) pointed out that the Chinese seem to easily adopt basic and user friendly technology such as Short Message Service (SMS) rather than more advanced but less user friendly ones such as Wireless Application Protocol (WAP). With this point in mind, the Chinese are expected to attach more importance on effort expectancy than consumers from the other developed countries do.

\section{Performance expectancy (PE)}

Performance expectancy is summed up as "the degree to which an individual believes that using the system will help him or her to attain gains in job performance". Scholars from information system research have constructed a unified model that summarizes the factors influencing user acceptance and behavior within information systems, known as the Unified Theory of Acceptance and Use of Technology (UTAUT) (Venkatesh et al., 2003). The contributors to the UTAUT have suggested that the core determinants performance expectancy in his model can be used to explain actual usage of information technologies.

According to the UTAUT, performance expectancy that can influence the use behavior in information systems, as Knowledge sharing systems are information and communication systems designed to support and enhance knowledge sharing activities, (Carlsson, 2003; Feng et al., 2004); therefore, research results from the area of information systems can inform us as to what factors might influence people's behavior within knowledge distribution systems. A modified version of this model is adopted in this study to build a guiding framework. For the purpose of this study, use behavior intention is replaced. By adapting the UTAUT to the particular factor to examine for this study.

According to Park (2003) performance expectancy analysis the perception of people perceive a system, such as the Internet or mobile technology, is useful in achieving their goals in terms of job performance. The concept of performance expectancy has been considered the most controlling tool for explaining the intention to use the system regardless of the types of IT, be it mandatory or voluntarily. While there is second predictor which has been general employed throughout technology adoption researches is effort expectancy, which explains how much people feel comfortable and find it easy to adopt and employ the system for their jobs. Performance expectancy is the extent to which an individual believes that utilizing the information system will assist him/her to attain benefits in job performance (Venkatesh et al., 2003). Performance expectancy is shown to be powerfully associated with behavioral intention to use m-Internet. To spice up the usage of $\mathrm{m}$ - Internet, the practitioners ought to build an endeavor to develop valuable functions and selection services that might facilitate to fulfill potential users' desires (Wang \& Wang, 2010). 


\section{Effort Expectancy (EE)}

Effort expectancy is defined as the degree of ease associated with the use of the system (Venkatesh et al., 2003). Based on the UTAUT, it is thought that individual acceptance of system will depend on whether or not the accessibility of m-Internet is easy and effortless. In addition, prior researchers have shown that constructs associated with effort expectancy will be stronger determinants of personal intention about using IT for helshe than they are for (Venkatesh \& Morris

2000; Venkatesh et al. 2003). This predictor which has been commonly employed throughout technology acceptance researches is effort expectancy, which explains how much people feel comfortable and find it easy to adopt and employ the system for their jobs Alamin, Yeoh, Warren, \& Salzman (2015)

Effort expectancy (EE) is found to be the most significant factor influencing the accounting information system adoption. Since the AIS is a relatively new accounting application in the Libyan context, it is not surprising that accountants' perceptions of whether the AIS is easy or difficult to adopt emerged as the most significant factor for its adoption. ABI to adopt the AIS may be compromised when they perceive an inability to do so. That is, accountants with lower EE perceptions towards adopting the AIS have a higher intention to adopt the AIS than those with higher EE perceptions. Furthermore, Park (2003) explains how people feel comfortable and find it easy to adopt and employ the system for their jobs. As the previous research on the Chinese mobile communication market which pointed out that the Chinese seem to with no trouble adopt basic and user friendly technology such as Short Message Service (SMS) rather than higher but less user friendly ones such as Wireless Application Protocol (WAP). Also, the Chinese are expected to connect more importance on effort expectancy than consumers from the other countries do.

According to Wang \& Wang (2010), the effort expectancy also has a significant influence on individual intention to use m-Internet. This means that the majority of users are concerned about the amount of time and effort needed to learn about and use it, if its usage entails complex user interfaces, slow response, and/or inconvenient connecting procedures, then its benefits would be greatly decreased. Thus, system providers should improve the user friendliness and ease of use of system so as to attract more users, As effort expectancy found to be a stronger determinant of intention for women than for men, and this result is in line with the findings of previous studies by Venkatesh \& Morris (2000); Venkatesh et al. (2003). in those studies it found that women tend to care much more about technological effort expended in the early stages of a new behavior. Therefore, should offer a user-friendly interface with a touch screen and even a voice recognition mechanism to connect to system. This could make women perceive system as easier to use and thus they would be more likely to adopt it in the future.

\section{Task-technology fit (TTF)}

Task-Technology Fit (TTF), Goodhue and Thompson (1995) suggested the TTF model that extends the TAM by in view of how the task affects users. More specifically, the TTF model describes that an innovation will give preference to individual all-around use, and innovation appropriation depends incompletely on how well the new innovation fits with the bolstered undertaking. Goodhue and Thompson (1995) further stated that technology is perceived as an instrument with which people do. Tasks are the actions of turning inputs into outputs done by individuals. Task characteristics such as variety, difficulty, and interdependence are related to an individual's dependence on using 
technologies. Thus, if the individuals think that the technology can help to perform well, they will perceive it as useful and important to them.

In the context of e-banking, task-technology fit refers to the ability of technology to assist employees in performing their tasks on the job. The higher the fit degree, the better performance may result. Specifically, TTF corresponds to the relationship of matching among task characteristics and employee abilities. Moreover, in order to use Task-technology fit (TTF), according to Goodhue, what is needed for user evaluations to be an effective measure of IS success is the identification of some specific user evaluation construct, defined within a theoretical perspective that can usefully link underlying systems to their relevant impacts. Goodhue proposes that user evaluations can be based upon the concept of task-technology fit. In his study, user evaluations were found to be influenced directly by system, task, and individual characteristics.

Goodhue, 1995 concentrated on the "user domain of IT-supported decision making". Based on this task domain, the TTF model discovered three main subtasks of workers who are using quantitative information to perform their tasks. The subtasks include: 1) recognizing needed data, 2) accessing identified data, and 3) integrating and interpreting accessed data. Furthermore, Goodhue identified several dimensions for every subtask. The development of TTF, Obviously, Task- Technology Fit, in turn, affects the outcome either Performance or Utilization. TTF models state that IT will be implemented if the available functions support or fit the user activities. Logically, experienced users will choose devices and methods that enable them to complete the task with the most net benefit. On the other hand, Information Technology which does not offer sufficient benefits will not be used. A common addition to a TTF model is Individual Abilities (Goodhue \& Thompson,

1995).

The insertion of character Abilities is on the whole supported by effort correction Theory and recent MIS studies in which Experience with particular IT is generally associated with higher operation of that IT. The core of a Task-Technology Fit Model is a formal construct known as Task- Technology Fit (TTF), which is the matching of the capabilities of the technology to the demands of the task, that is, the ability of IT to support a task (Goodhue \& Thompson, 1995).

\section{Facilitating Conditions (FC)}

Facilitating Conditions (FC) is the extent to which an individual trusts that an authoritative and specialized framework exists to bolster the framework (Venkatesh et al., 2003). Facilitating conditions in the UTAUT comprises of facilitating conditions, and compatibility from the TPB TAM, models, (Ajzen, 1985); Taylor \& Todd, 1995); Triandis, 1979); Venkatesh et al., 2003). Researchers in the field of technology studies e.g. Venkatesh et al. (2003); Moore \& Benbasat, (1991); Thompson et al. (1991); Chang et al. (2007); Taylor \& Todd (1995); Chau \& Hu, (2002); Venkatesh \& Speier (1999) found that the facilitating conditions construct has a positive effect on innovation use. They also found that it is a significant predictor of the technology use. In contrast, they found that it did not predict intention to use IT when both constructs, performance expectancy and effort expectancy are used in the same model. Within this facilitating conditions measured by the perception of being able to access required resources, as well as to obtain knowledge and the necessary support needed to use e-government services. It is also influenced by the perception of the technology fitting into the lifestyle of the user.

Baraghani (2008) said that facilitating conditions refer to the necessary resources and supports to perform a behavior, for example, time, money, expertise, hardware, 
software, network connection, etc. which assumes that usage is volitional. There is no barrier that would prevent an individual from using an IS facilitating conditions. Facilitating conditions only affect the actual behavior and does not influence perceived behavioral. Furthermore, Facilitating conditions refers to availability of physical (money, time) and technological resources for acceptance (Chirani \& Ghofrani, 2010). Innovative and individual features directly affect the rate of acceptance of adoption and facilitating conditions of the market indirectly, and due to feature of innovation and personal characteristics affect the rate of acceptance adoption of IT. If there are fewer resources available, naturally, lack of facilitating resources creates some obstacles for the use, and the presence of facilitating conditions encourages the number of uses. To do so, from the decomposed theory of planned behavior and the perceived behavioral control construct, the factor of facilitating conditions is taken into the model. Based on the study of Tan and Teo (2000), facilitating conditions can be broken down into two variables, in particular accessibility of technology support and accessibility of government support.

\section{Self-efficacy (SE)}

Self-efficacy is the trust in one's capabilities to mobilize the motivation, cognitive resources, and courses of action needed to meet given situational demands Bandura (1986). Self- efficacy also refers to one's interest and willingness to use and interact with information technology (Hasan, 2003). Self-efficacy plays an important role in affecting an individual's motivation and behavior. That is individuals' self-perception of their own capabilities to attain the standards that they have been pursuing has an impact on individual cognitive and behavioral reactions. Those individuals who lose their confidence about their capabilities are easily discouraged and fail, whereas those who are highly assured of their efficacy for goal attainment will intensify their efforts when their performances fall short and persevere until they succeed (Igbaria \& Iivari, 1995).

Among the various individual factors examined in the literature, computer selfefficacy has been identified as a key determinant of computer usage. Derived from the general concept of self- efficacy, computer self-efficacy refers to an individual's perceptions about his or her ability to use a computer to perform a computing task successfully, Bandura (1986). And self-efficacy has been shown to be associated with an individual's performance in computer training and technology acceptance (Compeau \& Higgins, 1995). Similar argument is suggested by Marakas et al. (1998) that computer self-efficacy affects not only an individual's perceptions of his or her ability to perform a computing task, but also his or her intentions toward future use of computers. However, in a study of electronic learning programs in information technology, it is found that computer self-efficacy, as a moderating factor, appeared to be a less salient factor to improve end-user satisfaction with e-learning systems, and this factor might also not directly affect end-user intention to continue using elearning system (Hayashi et al., 2004).

According to Bedard, Jackson, Ettredge, \& Johnstone (2003), User perceptions of computer self-efficacy have been shown to be important in their system perceptions, knowledge workers need both computer and task proficiency to apply a workplace system efficiently and effectively in performing their jobs. Thus, their perceptions of selfefficacy related to both the computer technology and the underlying task are likely to affect their perceptions about the system and their intentions to use it as intended by the system developers, find that self-efficacy perceptions positively affect ease of use perceptions for both groups prior to training, but this effect does not extend to perceived system usefulness, shows that as a group, preparers' self-efficacy perceptions (both computer and task) shifted 
during training, but those of reviewers did not. Generally, it is confirmed that computer selfefficacy is positively associated with perceptions of system ease of use. Furthermore according to Seneler, Basoglu, \& Daim (2010), users are positively influenced by their acquaintances, commercials and related news about online ticket reservation positively. Selfefficacy is also identified as a positive reason. Self-efficacy is the client judgment of one's capacity to utilize an item (Thong et al., 2004). In other words, self-efficacy is the user's perception about being satisfactory, effective, and efficient during product usage.

\section{Behavior intention}

Behavioral is motivational factors that capture how hard people are willing to try to perform a behavior (Chen et al., 2009 cited in Özer \& Yilmaz, 2011). TRA argued that individual behavior would be driven by behavioral intentions (Fishbein \& Ajzen, 1975). Fishbein and Ajzen defined behavior "as the individual's feelings about performing a behavior". On the other hand, subjective norm is explained as "an individual's perception of whether the behavior should be performed". This would be driven by the motivation that an individual has to comply with opinions from people who are important to the individual.

Behavioral is assumed to indicate how hard people would be willing to try, of how much of an effort they would be planning to exert, in order to perform the behavior. As a general rule, the stronger the intention to engage in a behavior, the more likely should be its performance (Sheppard, Hartwick et al., 1988). Behavioral is an essential factor in understanding behavioral willingness before a specific behavior is adopted. Behavioral indicates the expression induced during the actual behavioral process; this expression point out whether a particular behavior will be adopted or not. Behavioral intention is a requisite process in any type of actual behavior; it is a decision made previous to the adoption of behavioral (Fishbein \& Ajzen, 1975).

There are numerous studies that researched the forerunner calculates that influence individual's behavioral to purchase items or services. For instance, Asosheh, Bagherpour, Yahyapour, \& Asosheha (2008) carried out a study to investigate and explain the variables that influence a person's intention to adopt a user recommender system from the user viewpoint in Iran. The researcher analyzed many factors, which are supposed to affect a person's intention to adopt a banking recommender system such as, consumer's attitudes, perceived usefulness, personality, and perceived ease of use. The result revealed that perceived ease of use play the most significant role that affected user intention of using banking recommender system and of the factors the most important were attitude and perceived usefulness in order of importance.

Fusilier \& Durlabhji (2005) investigated the university student's behavior to use the internet. Questionnaires were distributed to 260 students in India. Despite consumer's attitude being considered as a key factor in determining intention, subjective norm appeared to be a more important factor in this study, which affected students' behavior to use the internet. This is maybe due to India's culture where the social pressure may compensate for less favorable behavioral in building intention

\section{RESEARCH FRAMEWORK AND HYPOTHESES DEVELOPMENT}

This chapter discusses the model and hypotheses development of this study. The model includes Unified Theory of Acceptance and Use of Technology (UTAUT) with TaskTechnology Fit (TTF). Followed by the hypotheses development from previous studies.

As shown in the research model (Figure 3.1, Appendix A), accountant's behavioral intention $(\mathrm{ABI})$ is the independent variable. Behavioral intention chosen causes its measures the determination of a person to act in a certain way (Davis et al., 1989). According to the 
UTAUT (Venkatesh et al. 2003), these four chosen factors is selected for these variables more are likely to influence end-users' behavioural intention towards the adoption and use of technology. These factors are performance expectancy (PE), effort expectancy (EE), facilitating conditions (FCs), Self-efficacy and Task-technology fit (TTF). The first three factors consistently influence behavioural intention to adopt technology, and could be important for CAS adoption (Aoun et al., 2010). Furthermore, the TTF model has been applied extensively in various IT adoption studies and has gained considerable empirical support. The focus of TTF is the fit between the attributes of technology and current practices and values. This concept has been found to significantly and positively influence the adoption of IT. The majority of available accounting technology applications are pre-packaged and inflexible to change their attributes easily to meet specific local or organisational requirements (Pulakanam and Suraweera, 2010; Grabski et al., 2011). Therefore, it is logical to theorise and study the effect of fit issues on the adoption of the AIS. Thus, technology fit (TF) factor is also included in this research model. This is a measure of how accountants perceive that the attributes of CAS fit well or align with their current accounting practices and values. This study also examines the effect of an individual's personality. Investigating the role of personality is important when studying the adoption of technology because studies have found that individuals' behaviors differ. One factor of individual behaviour is self-efficacy (SE). Researchers have found it to be a significant and important determinant of individuals' behavioral intention for IT adoption including in the accounting discipline (Dowling, 2009). This research added this factor to investigate whether accountants' SE influences their behavioral intention to adopt the AIS. SE is a measure of accountants' belief of capability to adopt CAS. Finally, industry type might moderate the influence of CPs and MPs on ABI. In short, the research model takes a comprehensive approach and includes a broader range of factors that might influence CAS adoption by accountants.

\section{Variables and Hypotheses development}

Based on above the proposed model, the following research hypotheses in the context of the use of critical success factors to examine the behavior intention of using computerized accounting systems (CAS) which are formulated as independent variables, Performance Expectancy, Effort Expectancy, Facilitating Conditions, Self-efficacy and Task-technology fit (TTF) ) as behavior intention of using (CAS).

\begin{tabular}{|c|c|}
\hline Hypothesises & Statements \\
\hline $\mathrm{H}: 1$ & $\begin{array}{l}\text { There is positive impact of Performance Expectancy (PE) on } \\
\text { Accountant }\end{array}$ \\
\hline H: 2 & $\begin{array}{c}\text { There is positive impact of Effort Expectancy (EE) on Accountant } \\
\text { Behavior intention of using (CAS) }\end{array}$ \\
\hline H: 3 & $\begin{array}{r}\text { There is positive impact of Task-technology fit (TTF) on Accountant } \\
\text { Behaviour intention of using (CAS) }\end{array}$ \\
\hline H: 4 & $\begin{array}{l}\text { There is positive impact of Facilitating Conditions (FC) on } \\
\text { Accountant }\end{array}$ \\
\hline H: 5 & $\begin{array}{l}\text { There is positive impact of Self-Efficacy (S-E) on } \\
\text { AccountantBehaviour intention of using (CAS) }\end{array}$ \\
\hline
\end{tabular}




\section{RESEARCH METHOD \\ Methods}

A methodology is classified as a technique that is used for conducting a research (Sekaran, 2003). It is a rule for resolving a problem, with specific components such as phrases, tasks, methods, techniques and tools. Thus, as stated in Kaplan \& Maxwell (2005), it is not just a collection of methods to perform a research. The main objective of the study will recognize and examine the critical success factors which are, Performance Expectancy, Effort Expectancy, Facilitating Conditions, Self-efficacy and Task-technology fit (TTF) of acceptance the Computerized Accounting Systems (CAS), to Accountant Behavior of using (CAS) aspects of accounting practices in Libyans organizations consisting with the objectives to achieves, the outline is crucial to decide the kind of data, the data accumulation strategy of the sort of study is explanatory study. In an Explanatory study the researcher begins with ideas about the possible causes of a phenomenon, i.e., the researcher develops hypotheses before collecting any data. The researcher then plans a study that can provide systematic evidence supporting (or not supporting) these initial ideas about cause. The data collected also provide systematic description.

\section{Population and sample}

The population and sampling as accountant's employee in Libyan cement manufacturers. The reason for choosing this sample population is that these people engage in using computerizing accounting system CAS for their transaction and daily activates, while the cements manufacturer is chosen because the cement industry in Libya currently is emerging industry that have raise its demand after oil and should be managed for better development, lastly, and I am Libyan citizen, thus, my duty as researcher to think about what is this industry need to be more sophisticated. The population of the study is the employee of cement manufactures in accounting department and finance which the total number are 240 . All of them is used as sample using census method. This sample is spread in three cities called AL-khumus, Tripoli city and Zlitan in Libya, and four manufactures named, AlMurgab with 60 employee in accounting department and Lubda with 55 employee in accounting department, Souk Al-khamis in Tripoli city with 48 employee in accounting department, and Zalitan in Zlitan city with 77 employee in accounting department. These cities are chosen as they have the largest manufactures in Libya and have most quantity of cements production.

\section{Instrument Administration}

Questionnaire items are adapted from the UTAUT study of Morris, Hall, Davis, Davis, \& Walton, (2003) and previous study from Misron, Shaffiei, \& Hamidi, (2011). These items represent independent and dependent variables utilized in the current study. Questionnaire items are to measure the behavioral intention of employees to using CAS. Other than wording modifications to fit the specific technology studied in this study, no changes are made on the user acceptance scale. All items use seven point Likert scale, where $1=$ completely disagree, $2=$ moderately disagree, $3=$ somewhat disagree, $4=$ neutral (neither disagree nor agree), $5=$ somewhat agree, $6=$ moderately agree, and $7=$ completely agree.

\section{Hypotheses Test}

Hypotheses test is made based on research purposes. Hypotheses test is used to determine whether a variable is significant or not. Furthermore, it is used to find out whether there is an influence of (significant) or not between the exogenous latent variables to endogenous latent variables, to test the significance of the t-test statistics. 
For testing hypothesis, alpha is $5 \%$ and power is $80 \%$, if the value of the coefficient path indicated by the statistic $\mathrm{T}$ ( $\mathrm{T}$ - statistic ) is $>1.96$, the alternative can be supported

\section{FINDING AND DISCUSSION}

\section{Description of Respondents and Variables}

The 240 questionnaires were distributed to 240 accountants of four cement manufacturers in Libya based on the sampling design. From these questionnaires, 189 were completed and returned or the response rate is about $79 \%$. The following table describes demographic statistics of the resondents: the breakdown of the respondents by gender, that $75.60 \%$ of the respondents is male and $24.40 \%$ is female, while based on age, most of the respondents is 20-29 years old by $46 \%, 42.30 \%$ is between $30-39$ years old, and the remaining $11.65 \%$ is above $40-49$ years old. This indicates that the majority of the respondents has considerable work experience. Furthermore, based on the above, 53.90 $\%$, has Diploma degree, $33.80 \%$ has bachelor degrees and $12.30 \%$ has master degree. The results also indicates that $23.20 \%$ of the respondents is Assistant accountant, 58.20\% Accountant, and $18.65 \%$ Senior Accountant. Furthermore, $67.72 \%$ of the respondents has experience less than 1 year. This is because most of the respondents' age ranges 20-29 years old, $20.63 \%$ has experience between 2 to 15 years, and the remaining $0.8 \%$ has never used IT, and more than 6-10 years around $13.00 \%$.

\section{Partial Least Square (PLS) Analysis}

Analysis of the data was done by using the PLS (partial least squares method), which is one of the SEM techniques. Structural Equation Modeling (SEM) techniques such as Lisrel and Partial Least Squares (PLS) are second generation data techniques that can be used to test the extent to which because research meets recognized standards for high quality statistical analysis (Gefen, 2000). SEM enables researchers to answer a set of interrelated research questions in a single, systematic and comprehensive analysis by modeling the relationships among multiple and dependent constructs simultaneously. This capability for simultaneous analysis differs greatly from most first generation regression models such as linear regression, ANOVA, and MANOVA, which can analyze only one layer of linkages between independent and independent variable at a time. Thus, the current study uses testing measurement model based on reflective construct. Linear structural model testing made to look at the relationship between the constructs, the significant value and R-square of the research model. Structural models were evaluated using the $\mathrm{R}$-square, and for the impact independet latent variable into dependent latent variable, it used $t$ test and the significance of the coefficient parameters of structural lines. In this study, Partial Least Square (PLS) method is used to look at the structural relationships to analyze this study; it uses a six of hypothesis by using Partial Least Square (PLS), as presented as follows:

\section{Evaluations Model (Outer Model) Convergent Validity}

Validation of the four capabilities leading to positional advantages based upon diverentiation with a complementary measure of strategy (instrument of Govindarajan, 1988) where the higher the score, the more the Wrm follows a diVerentiation strategy. This estimate is done by seeking at the value of loading factor on each indicator. If the value is larger than 0.500 , it can be assumed that such indicators are valid. The test results in Table 5.2 (Appendix B) shows the entire value of the loading factor for each indicator that is above than 0.5 , so we know that all of indicator for each construct has convergent validity 


\section{Discriminant Validity}

Examination of discriminant validity between the dimensions, and among the four dimensions of capabilities are done using a series chi-square difference tests between two dimensions at a time by constraining the estimated correlation parameter to 1.0. To assess discriminated validity of the measurement model in PLS, an average variance extracted (AVE) analysis should be conducted (Gefen and Straub 2005). AVEs can be calculated using the bootstrap technique offered in Smart PLS. In an AVE analysis, this evaluation is done by using the average value of the variance extracted ( AVE), Evaluation of measurement model with square root of AVE is by comparing the value of AVE with a comparison value. If the value AVE is greater than 0.500 , then the discriminated validity is well achieved. These values are normally used to assess the discriminant validity of measures and to be determined by applying the PLS. Based on Table 5.3 (Appendix B) it observed that the value of the AVE on Performance Expectancy (X1) is 0.8571, Effort Expectancy (X2) is 0.8573 , Task-technology fit (X3) is 0.7910 , Facilitating Conditions (X4) is 0.9530, Self-Efficacy (X5) is 0.8678, and Behavior intention (Y1) is 0.8469, while, The AVE value of all variable is greater than 0.500 . Therefore, it can be said that in discriminated validity, the measurement model is good.

\section{Reliability}

Reliability is examined using the Cronbach's alpha values. As shown in table 5.4 (Appendix C) most of these areabove 0.7; this indicates a commonly acceptable level for explanatory research, Evaluation models using alpha chronbach's measurement is to determine whether the construct has a high reliability or not. Alpha chronbach's values which greater than 0,600 indicates that constructs is reliable.

From Table 5.4 (Appendix C), it clear that the value of the alpha chronbach's on Performance Expectancy (X1) is 0.872, Effort Expectancy (X2) is 0.879, Task-technology fit (X3) is 0.795, Facilitating Conditions (X4) is 0.959, Self-Efficacy (X5) is 0.798, and Behavior intention (Y1) while Behavior intention of using (CAS) is0.721. The alpha chronbach's value of all variable is greater than 0.600 and it can be said that the measurement model is reliable as each items show above 0.7 . It seems that this study provides more reliable instruments because most of the score is higher (Doll and Torkzadeh,1988).

\section{Evaluation Structural Model (Inner Model)}

Evaluation Structural Model (Inner Model) for assessing the Inner model is looking at the relationship between latent variables to see the results of parameter estimation path coefficients and significance levels. The coefficient of determination ( $\mathrm{R}$ -square ) obtained from the model of Performance Expectancy (X1), Effort Expectancy (X2), Task-technology fit (X3), Facilitating Conditions (X4), Self-Efficacy (X5), and Behavior intention (Y1) variable is amounted to 0.914. So it can be explained that these Behavior intention ( Y1 ) variable can be explained by Performance Expectancy (X1), Effort Expectancy (X2), Task-technology fit (X3), Facilitating Conditions (X4), SelfEfficacy (X5) variable is amounted to $98.3 \%$ and the remaining $1.7 \%$ is influenced by other variables outside the research.

Table 5.5 R-square Result

\begin{tabular}{|c|c|}
\hline Variable & R Square $\left(\mathrm{R}^{2}\right)$ \\
\hline$(\mathrm{Y} 1)$ & 0.9834 \\
\hline
\end{tabular}




\section{Testing Hypothesis}

Hypotheses testing are used to test the hypotheses developed in the model, Testing criteria states that it happens if For testing hypothesis at alpha $5 \%$ and power $80 \%$, if the value of the coefficient path indicated by the statistic $\mathrm{T}$ ( $\mathrm{T}-$ statistic $)$ is $>1.96$, the alternative can be supported. On the other hand, Hypotheses testing can be known through the T-statistics in the following table. Based on the results of statistical tests that have been used, all hypotheses tested have met the requirements or can be used as a measurement model in this study .

The results of statistical tests that have been used, all hypotheses are tested to meet the requirements or can be used as a measurement model in this study. Based on the results of hypothesis testing, presented the following results. Models are formed from the hypothesis in this study for testing hypothesis at alpha $5 \%$ and power $80 \%$ if the value of the coefficient path indicated by the statistic $\mathrm{T}(\mathrm{T}-$ statistic $)$ is $>1.96$, the alternative can be supported.

Hypothesis number (1) predicted that there is positive impact of Performance Expectancy (X1) on behavior intention of using CAS ( Y1 ) as a linkage. Table 5.6 (Appendix C) show that T-Statistics is $>1,96$, that indicates the impact Performance Expectancy (X1) on Behavior intention (Y1) is positive impact as the structural path coefficient between the Performance Expectancy (X1) construct and Behavior intention of using CAS (Y1) construct is statistically significant at $\alpha=0.05(0.08248)$. This means that if Performance Expectancy (X1) increases, then and Behavior intention of using CAS (Y1) will increase and vice versa.

Hypothesis number (2) predicted that there is positive impact of Effort Expectancy (X2) on Behavior intention (Y1). The table 5.6 (Appendix C) shows that T-Statistics is $<1,96$, that indicates the impact Effort Expectancy (X2) on Behavior intention of using CAS (Y1) with Behavior intention (Y1) is not significant. The structural path coefficient between the Effort Expectancy (X2) construct and the Behavior intention of using CAS (Y1) construct is statistically not significant at $\alpha=0.05(-0.02742)$. This means that if Effort Expectancy (X2) increase will not affect the Behavior intention of using CAS (Y1).

Hypothesis number (3) predicted that there is positive impact of Task technology Fit(X3) to Behavior intention of using CAS (Y1) with Behavior intention (Y1). Table 5.6 (Appendix C) shows that T-Statistics is $>1,96$, that indicates the impact Task technology Fit (X3) of using CAS (Y1) with Behavior intention (Y1) is significant. The structural path coefficient between the Task technology Fit (X3) construct and the Behavior intention of using CAS (Y1) construct is statistically significant at $\alpha=0.05(0.10645)$. This means if Task technology Fit (X3) increases, then Behavior intention of using CAS (Y1) will increase and vice versa.

Hypothesis number (4) predicted the positive impact of Facilitating Conditions (X4) with Behavior intention (Y1). Table 5.6 (Appendix C) shows that T-Statistics is $>1,96$, this indicates that the impact Facilitating Conditions (X4) using CAS ( Y1 ) with Behavior intention (Y1) is significant. The structural path coefficient between the Facilitating Conditions (X4) construct and the Behavior intention of using CAS (Y1) construct is statistically significant at $\alpha=0.05$ (0.31563). This means if Facilitating Conditions (X4) increases, then Behavior intention of using CAS (Y1) will increase and vice versa.

Hypothesis number (5) predicted the positive impact of Self-Efficacy (X5) with Behavior intention (Y1). Table 5.6 (Appendix C) shows that T-Statistics is $>1,96$, indicates 
that the impact Self-Efficacy (X5) to Behavior intention of using CAS (Y1) with Behavior intention (Y1) is significant. The structural path coefficient between the Self-Efficacy (X5) construct and the Behavior intention of using CAS (Y1) construct is statistically significant at $\alpha=0.05$ (0.59266). This means if Self-Efficacy (X5) increases, then Behavior intention of using CAS (Y1) will increase and vice versa.

\section{DISCUSSION}

The objective of this study is to test and answer the research questions. Based on hypothesis testing and findings of this study, the result of the analysis on the Performance Expectancy, Effort Expectancy, Task-technology fit, Facilitating Conditions, Self-Efficacy, and Behavior intention of using CAS is presented as follow. Furthermore, the validity on findings is supported by putting forward some arguments from academic journals as disclosed previously.

\section{Performance Expectancy (PE) positively impacts on Accountant Behavior Intention.}

The first stage of the analysis is the main predictor's performance expectancy (PE). The objectives of this study is to identify the impacts of performance expectancy (PE) on accountant behaviour intention of using (CAS). This section discusses the results based on the findings from the analysis. Performance expectancy is measured by the perceptions of on accountant behaviour intention of using (CAS). In term of benefit, such as saving time, money, effort, fast communication, and improving the quality of accounting services, Performance expectancy focuses on task accomplishments. Performance expectancy has the highest predictive power of behavioural intention.

The result indicated that the accountants intend to use (CAS) and expect the system improve their professional performance. Because of this tendency, the accountants are more likely motivated by task-related performance, and thus have higher performance expectancy, then this study is in agreement with previous studies like Carlsson, (2003); \& Feng et al. (2004). According to them, performance expectancy influences use behaviour in information systems as knowledge sharing systems. Similarly, Park (2003) stated that performance expectancy effect to the perception of people perceive a system, such as the Internet or mobile technology, and it is useful in achieving their goals in terms of job performance.

The performance expectancy is the most positive effect tool for explaining the intention to use the system regardless of the types of IT. Performance expectancy has been identified as a good predictor of behavioural intention to adopt using IT (Venkatesh et al., 2003). Adjustment performance expectancy to an m-Internet context implies that mobile users will think that m-Internet is beneficial because it enables them to achieve their daily jobs easier and with more soften or even assistant growth up their work output. Same as study by (Wang \& Wang, 2010) found that performance expectancy is shown to be strongly related to behavioural intention to use m-Internet. To boost the usage of $\mathrm{m}$ Internet, m-Internet practitioners should make an effort to develop valuable functions and variety services that could help to fulfil potential users' needs. It can be concluded that the analysis showed that predicted there is a significant positive impact of performance expectancy (PE) on accountant behaviour intention of using (CAS)

\section{Effort Expectancy (EE) positively impacts on Accountant Behaviour Intention.}

Effort Expectancy is the degree of ease connected with the application of the system (Marchewka et. al., 2007; Rogers, 2003; Venkatesh et al., 2003; Davis, 1989). Effort 
expectancy is the degree of ease associated with the use of the system (Venkatesh et al., 2003). Venkatesh et al., (2003) identified three constructs from the eight models that make up the concept of effort expectancy: perceived ease of use, complexity, and ease of use. Additionally, Marchewka et al., (2007) claimed that this constructs can be significant in determining user acceptance of information technology. According to Kijsanayotin et al., (2009), the concept is similar to the perceived ease of use construct in TAM and the IDT models and the complexity of technology construct in the MPCU model.

In this study, effort expectancy is measured by the perceptions of accountants to behaviour intention of using CAS in Libyan cement manufacturing, and the result showed that the impact Effort Expectancy on accountant behaviour intention of using (CAS) is not significant and is not supported as the table 5.7. (Appendix C) It could be because two reason. First, the accountants is relatively new using CAS or computer system and don't have knowledge about IT that using a particular system would lessen their effort and as most of them has less than one year experience of using technology. Second, they probably felt that traditional accounting system with papers and hand documents are still easier and very comfortable with them that issue of use might not arise. More specifically, most of the responders age between is 20 t0 29 years old, so its relatively few experience in working as accountant, then this result of this study it can be concluded that there is not positive impact of Effort Expectancy and on accountant behaviour intention of using (CAS). There are many scholars (Davis,1989; Moore and Benbasat, 1991; Thompson et al., 1991; Chang et al., 2007; Agarwal and Prasad, 2000; Schaper and Pervan, 2007; Gupta et al., 2008; Al-Gahtani et al., 2007) found that effort expectancy has a significant influence on intention to use behaviour. In contrast, Chau and $\mathrm{Hu}$ (2002), argued that effort expectancy does not have significant influence to intention to use behaviour. Therefore, similar to the study on the impact on intention to use the Qatari e-government services, the author suggests extending similar initiatives to other Arab countries.

\section{Task Technology Fit (TTF) positively impacts on Accountant Behaviour Intention.}

Goodhue and Thompson explained that technology is viewed as a tool by people after they perform their tasks with it. Tasks area unit the actions role out by people in turning inputs into outputs. Task characteristics in terms of selection, difficulty, and reciprocity might link to an individual's reliance on mistreatment technologies, and if the people notice that the technology will facilitate them performs well, they're going to understand it as helpful and necessary to them.

TTF model depicts that a technology have a positive impact on individual performance if it's well utilised, and technology adoption depends partly on however well the new technology fits with the task it supports task-technology. The results show that is not supported by previous studies og Goodhue \&amp; Thompson (1995)( H.Alden, E. Sukoharsono \& Z.Baridwan 2015). And therefore the finding of this study is in step with previous studies. Additionally, Goodhue and Thompson (1995) hypothesized that a high task-technology match would completely influence the use of knowledge systems. Likewise, alternative authors confirmed positive relationships between TTF of specific technologies and utilization constructs rather than employing a utilization construct. Klopping et al. (2004) found conjointly robust support for a direct correlation between TTF and intention to use.

The analysis of this study showed that predicted positive impact relationship between Task Technology Fit (TTF) on accountant behaviour intention of using (CAS), 
that indicates there is positive impact Task technology Fit (TTF) on accountant behaviour intention of using (CAS) and it is supported.

\section{Facilitating Condition (FC) positively impacts on Accountant Behaviour Intention.}

Facilitating conditions are the degree to which an individual believes that an organisational and technical infrastructure exists to support the system (Venkatesh et al., 2003). Based on (Ajzen, 1985; 1991; Taylor and Todd, 1995; Triandis, 1979; Venkatesh et al., 2003). Researchers in the field of technology studies (e.g. Venkatesh et al., 2003; Moore and Benbasat, 1991; Thompson et al., 1991; Chang et al., 2007; Taylor and Todd, 1995; Chau and $\mathrm{Hu}, 2002$; Venkatesh and Speier, 1999) found that the facilitating conditions construct has a positive effect on innovation use. They also found that it is a significant predictor of the technology use. In contrast, they found that it did not predict intention to use IT. Furthermore, Alawadhi \& Morris (2008) stated that facilitating conditions are significant in the adoption of e government services in Kuwait. Alamin, Yeoh, Warren, \& Salzman (2015) indicated that five major factors (i.e., effort expectancy, perceived technology fit, facilitating conditions, self- efficacy, and coercive pressure) play a significant role in AIS adoption where Facilitating conditions (FC) are also found to be a significant antecedent of influencing the AIS adoption. The study of Factors influencing teachers' intention to use technology: Model development and test (Teo, 2011), as defined refers to the perceptions of the real world artefacts of the technology and the resources. The results indicated that the facilitating conditions had a greater influence on teachers' intention to use technology than subjective norm and its found positive influence. The analysis of this study showed that predicted positive impact relationship between Facilitating conditions (FC) on accountant behaviour intention of using (CAS) that there is positive impact Facilitating conditions (FC) on accountant behaviour intention of using (CAS) and it's supported.

\section{Self-Efficacy (SE) positively impacts on Accountant Behaviour Intention.}

Self-efficacy, the principal idea of social learning theory, entails that one ought to alert to him/ herself and also the individual ought to act in step with true by examination the performance that he/she is needed to show with his/he performance that affects individuals' interests toward laptops and their need to use a computer (Gurcan, 2005). Additionally, it emphasizes that once facing difficulties in computer-related tasks, one ought to be determined to beat these difficulties.

Definition of Self-efficacy is a person's belief in their ability to accomplish a selected task (Compeau and Higgins, 1995). Bandura (1986) developed the idea of Selfefficacy from the Social literature; Self-efficacy isn't a measurable idea at a general level since talents area unit domain specific. Thus, new measures of self-efficacy should be developed for every totally different application of the construct. Compeau and Higgins (1995) stated that the conceptualization of international intelligence agency provides a live that's specific to automatic data processing system usage skills, however sufficiently general to be applied to any automatic data processing system. As a result, it is normally utilized in laptop self-efficacy studies. In line with Bandura, self-efficacy is tormented by past expertise. Thus, the result indicates that the accountants would intend to adopt using (CAS) by self-efficiency, then the analysis of this study showed that predicted positive impact relationship between self-efficiency(SE) on accountant behaviour intention of using (CAS). The finding indicates that there is positive impact of self-efficiency (SE) on accountant behaviour intention of using (CAS) and it's supported. 


\section{CONCLUSION AND RECOMMENDATION Conclusion}

This chapter summarizes conclusion in the light of the research findings. There is a clear need for understanding of behavior intention to Using Computerized Accounting Systems (CAS) In Cement Manufactures in Libya. If Using Computerized Accounting Systems (CAS) in Cement Manufactures in Libya is successfully gained. This study aims at providing readers and practitioners with the findings of the behavior intention to Using Computerized Accounting Systems (CAS) In Cement Manufactures in Libya. The study focuses on the accountants of Manufactures in Libya institutions for implementing CAS. It is found that Libyan Cement Manufactures accountants is possible to adopt and implement technological alternatives to traditional manual procedures if they find the new process to be easier to use and help them accomplish their work tasks effectively. The analysis of hypothesis shows that there is a possibility to implement of Using Computerized Accounting Systems (CAS) in Cement Manufactures as reflected on the results of this study.

The analysis presented is based on a sample of respondents and considers the impact of numerous variables are analyzed and tested using the construct of variables which are, Performance Expectancy, Effort Expectancy, Facilitating Conditions, Self-efficacy and Task-technology fit (TTF) to accountant Behavioral Intentions (ABI) of using (CAS) aspects of accounting practices in Libyans Cement Manufactures. Based on performance expectancy as the extent to which an individual believes that utilizing the information system will assist him/her to attain benefits in job performance and Performance expectancy is revealed to be powerfully associated with behavioral intention to use CAS. However, Effort Expectancy (EE) defined as the degree of ease associated with the use of the system is found to be have no significant influencing the accounting CAS system adoption. Furthermore, Task-Technology Fit (TTF) as Goodhue and Thompson (1995) suggested that the TAM by in view of how the task affects uses, Task-technology fit (TTF) shows that the higher the degree of the fit, the better performance may result. Specifically, TTF corresponds to the relationship of matching among task characteristics and accountants abilities. While, facilitating conditions refer to the necessary resources and supports to perform a behavior. Similarly, Self-efficacy refers to one's interest and willingness to use and interact with information technology (Hasan, 2003). Self-efficacy plays an important role in affecting an individual's motivation and behavior, then Behavioral indicates how hard people would be willing to try, of how much of an effort they would be planning to exert, in order to perform the behavior. As a general rule, the stronger more likely should be its performance.

\section{Recommendation}

Based on the study and observation process, I formulate several recommendations for the related parties:

1. The company should conduct IT training for the employees (e.g. courses on IT languages or training short course). This is believed to be vital because the experience of IT training programs so far are pitched at too low a level to prepare staff for the more complex procedures that they have to manage with technologies.

2. The company should reduce the difficulties. It is recommended that software of accounting should be developed to be more user-friendly software that can be easily used for those who have lack of the IT expertise and, since Libyan speaks Arabic, these software programmers should also include Arabic language features. 
55 The Influence of the critical factors on the behaviour.......

3. The company should increase accountant's knowledge on modem technologies through various communication channels (e.g. conferences and workshops).

4. For future researcher, I recommended to find more the relation between positive perception of accountant's employee about their jobs and business performance related IT and or profitability of their organization

5. The government also should improve the existing infrastructure at the local and national level to increase the number of PC and core IT requirements.

\section{REFERENCES}

Alamin, A., Yeoh, W., Warren, M., \& Salzman, S. (2015). an Empirical Study of Factors Influencing ACCOUNTING INFORMATION SYSTEMS ADOPTION. Twenty-Third European Conference on Information Systems (ECIS), 11.

Al-Shafi, S., \& Weerakkody, V. (2010). Factors affecting e-government adoption in the state of Qatar. Proceedings of the European and Mediterranean Conference on Information Systems Abu Dhabi UAE 1213 April 2010, 2010, 1-23. http://doi.org/10.1179/204264411X12961227987886

Asosheh, A., Bagherpour, S., Yahyapour, N., \& Asosheha, a. (2008). Extended Acceptance Models for Recommender System Adaption, Case of Retail and Banking Service in Iran. WSEAS Transactions on Business and Economics, 5(5),189-200.

Baraghani, S. N. (2008). MASTER' S THESIS Factors Influencing the Adoption of Internet Banking MASTER' S THESIS Factors Influencing the Adoption of Internet.

Bedard, J. C., Jackson, C., Ettredge, M. L., \& Johnstone, K. M. (2003). The effect of training on auditors' acceptance of an electronic work system. International Journal of $\begin{array}{llll}\text { Accounting } & \text { Information } & \text { Systems, } & \text { 227-250. }\end{array}$ http://doi.org/10.1016/j.accinf.2003.05.001

Chirani, I., \& Ghofrani, Y. R. (2010). Designing a model for explanation of the internet banking acceptance rate. ICIME 2010 - 2010 2nd IEEE International Conference on Information Management and Engineering, 3(21), 627-633. http://doi.org/10.1109/ICIME.2010.5478241

Dacosta, B. A., Frimpong, E., Agyei, J., Frimpong, B. O., \& Duah, R. (2012). The impact of the use of computerised accounting systems in financial reporting, a case study of rural banks, ghana benard. PhD Dissertation, (June), 1-73.

Elekwa, P. N. N., \& Innocent, O. (2013). An Analysis of Computerized Accounting and Payrolling System on Monthly Emolument in Nigerian Local Government: International Journal of Accounting Research, 1(3), 16-28.

Fowzia, R., \& Nasrin, M. (2011). Appreciation of Computerized Accounting System in Financial Institutions in Bangladesh. World Review of Business Research, 1(2), 1-9.

Ghasemi, M., Shafeiepour, V., Aslani, M., \& Barvayeh, E. (2011). The impact of information technology (it) on modern accounting systems. Procedia - Social and Behavioral Sciences, 28, 112-116. http://doi.org/10.1016/j.sbspro.2011.11.023

Gido, J., Clements, J. P., Calhoun, J. W., Sabatino, J., Dauksewicz, J., Shipp, L., ... Shirley, S. J. (2009). Licensed to: Chapters User Licensed to: Chapters User Printed in the United States of America. Successful Project Management. http://doi.org/0-495-91356-1

Good, U. (2013). Factors Determining the Purchase Intention of Bank Services in the Republic of Yemen Doctor of Philos. Uum, (January).

Goodhue, D. L., Thompson, R. L., \& Goodhue, B. D. L. (1995). Task-Technology Fit and Individual Performance. MIS Quarterly (Management Information Systesm), 19(2), 213236. http://doi.org/10.2307/249689 
Goodhue, D. L., Wixom, B. H., \& Watson, H. J. (2002). Realizing Business Benefits Though CRM: Hitting the Right Target in the Right Way. MIS Quarterly Executive, 1(2), 79-94. Retrieved from http://misqe.org/ojs2/index.php/misqe/article/viewFile/28/23

H.A. Riyadh , E. G. Sukoharsono \& Z. Baridwan. 2015. "E-Banking Implementation and Technology Acceptance in the Rafidain and Rasheed Banks in Iraq : An Employee Perspective."

Hong, K. K., \& Kim, Y. G. (2002). The critical success factors for ERP implementation: An organizational fit perspective. Information and Management, 40(1), 25-40. http://doi.org/10.1016/S0378-7206(01)00134-3

Lin, H., Wu, C., \& Yang, J. (2011). A Productivity Review Study on Theory of Reasoned Action Literature Using Bibliometric Methodology, 8(March), 38-42.

Mishra, D., Akman, I., \& Mishra, A. (2014). Theory of Reasoned Action application for Green Information Technology acceptance. Computers in Human Behavior, 36, 29-40. http://doi.org/10.1016/j.chb.2014.03.030

Misron, M. M., Shaffiei, Z. A., \& Hamidi, S. R. (2011). Measurement of user's acceptance and perceptions towards campus management system (CMS) using Technology Acceptance Model (TAM). International Journal of Information Processing and Management, 2(4), 34-46. http://doi.org/10.4156/ijipm.vol2.issue4.4

Morris, M. G., Hall, M., Davis, G. B., Davis, F. D., \& Walton, S. M. (2003). USER ACCEPTANCE OF INFORMATION TECHNOLOGY: TOWARD A UNIFIED VIEW. MIS Quarterly, 27(3), 425-478. http://doi.org/10.2307/30036540

Özer, G., \& Yilmaz, E. (2011). Comparison of the theory of reasoned action and the theory of planned behavior: An application on accountants' information technology usage, 5(1), 50-58. http://doi.org/10.5897/AJBM10.389

Park, J. (2003). Adoption of mobile technologies for chinese consumers, 196-207.

Ramburuth, A. P. (2008). EXTENDING THE TASK-TECHNOLOGY FIT MODEL WITH SELF-EFFICACY CONSTRUCTS Mark, 1-14.

SALEH, S. A. (2011). a Study on the Use of Computerised Accountinting Systems. Universiti Utara Malaysia,.

Seneler, C. O., Basoglu, N., \& Daim, T. U. (2010). An empirical analysis of the antecedents of adoption of online services: A prototype-based framework. Journal of Enterprise Information Management, 23(4), 417-438. http://doi.org/10.1108/17410391011061753

Wang, H.-Y., \& Wang, S.-H. (2010). User acceptance of mobile internet based on the Unified Theory of Acceptance and Use of Technology: Investigating the determinants and gender differences. Social Behavior and Personality: An International Journal, 38(3), 415-426. http://doi.org/10.2224/sbp.2010.38.3.415

Curtis, G. (1995). Business Information Systems: Analysis, Design and Practice. Wokingham: Addison-Wesley Publishing company 
57 The Influence of the critical factors on the behaviour.......

\section{APPENDIX A}

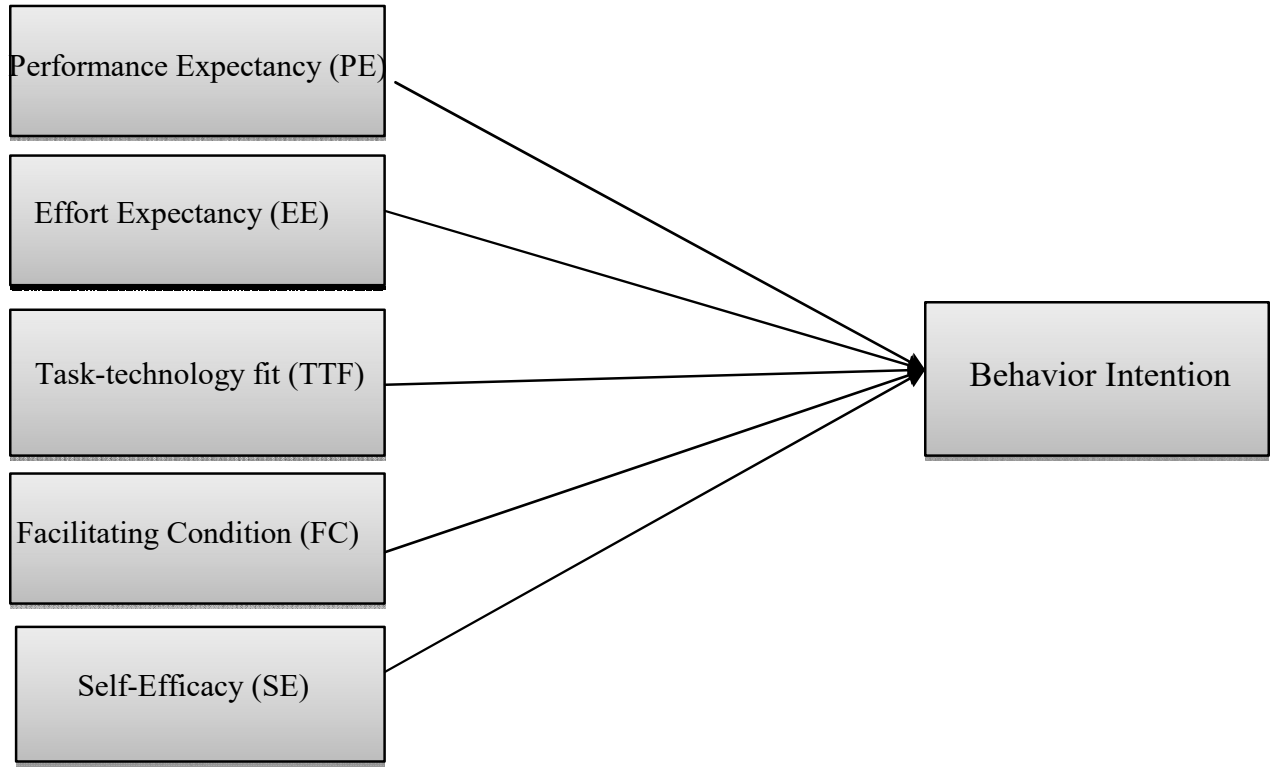

Figure 3.1 Research model

Table 4.1 Details of population and samples

\begin{tabular}{|l|l|l|c|}
\hline Manufactures name & \multicolumn{1}{|c|}{ Location } & \multicolumn{1}{c|}{$\begin{array}{c}\text { Total } \\
\text { Accounti }\end{array}$} & Manufactures using CAS \\
\hline Al- Murgab & AL-khumus city & 60 employee & Fair \\
\hline Lubda & AL-khumus city & 55 employee & Fair \\
\hline Souk Al-khamis & Tripoli city & 48 employee & Fair \\
\hline Zalitan & Zalitan city & 77 employee & \\
\hline & The total & 240 employee & \\
\hline
\end{tabular}




\section{APPENDIX B}

Table 5.2 the entire value of the loading factor

\begin{tabular}{|c|c|c|c|}
\hline Variable & & Outer Loading & Result \\
\hline \multirow{4}{*}{$\begin{array}{l}\text { Performance Expectancy } \\
\text { (X1) }\end{array}$} & $\mathrm{x} 1$. & 0.858 & Valid \\
\hline & $\mathrm{x} 1$. & 0.932 & Valid \\
\hline & $\mathrm{x} 1$. & 0.808 & Valid \\
\hline & $\mathrm{x} 1$. & 0.823 & Valid \\
\hline \multirow{4}{*}{$\begin{array}{l}\text { Effort Expectancy } \\
\text { (X2) }\end{array}$} & $\mathrm{x} 2$. & 0.883 & Valid \\
\hline & $\mathrm{x} 2$. & 0.781 & Valid \\
\hline & $\mathrm{x} 2$. & 0.912 & Valid \\
\hline & $\mathrm{x} 2$ & 0.846 & Valid \\
\hline \multirow{4}{*}{$\begin{array}{l}\text { Task-technology fit } \\
\text { (X3) }\end{array}$} & x3. & 0.884 & Valid \\
\hline & $\mathrm{x} 3$. & 0.740 & Valid \\
\hline & $\mathrm{x} 3$. & 0.829 & Valid \\
\hline & $\mathrm{x} 3$. & 0.697 & Valid \\
\hline \multirow{4}{*}{$\begin{array}{l}\text { Facilitating Conditions } \\
\text { (X4) }\end{array}$} & $x 4$. & 0.965 & Valid \\
\hline & $\mathrm{x} 4$. & 0.985 & Valid \\
\hline & $\mathrm{x} 4$. & 0.933 & Valid \\
\hline & $\mathrm{x} 4$. & 0.925 & Valid \\
\hline \multirow{3}{*}{$\begin{array}{l}\text { Self-Efficacy } \\
\text { (X5) }\end{array}$} & $\times 5$. & 0.948 & Valid \\
\hline & $\mathrm{x} 5$. & 0.836 & Valid \\
\hline & $\times 5$. & 0.813 & Valid \\
\hline \multirow{3}{*}{$\begin{array}{l}\text { Behavior intention } \\
\text { (Y1) }\end{array}$} & $\mathrm{y} 1$. & 0.780 & Valid \\
\hline & $\mathrm{y} 1$. & 0.930 & Valid \\
\hline & $\mathrm{y} 1$. & 0.823 & Valid \\
\hline
\end{tabular}

Table 5.3 Average Variance Extracted (AVE) Result

\begin{tabular}{|l|c|}
\hline \multicolumn{1}{|c|}{ Variable } & $\begin{array}{c}\text { Average Variance } \\
\text { Extracted (AVE) }\end{array}$ \\
\hline Performance Expectancy (X1) & 0.8571 \\
\hline Effort Expectancy(X2) & 0.8573 \\
\hline Task-technology fit (X3) & 0.7910 \\
\hline Facilitating Conditions (X4) & 0.9530 \\
\hline Self-Efficacy (X5) & 0.8678 \\
\hline Behavior intention (Y1) & 0.8469 \\
\hline
\end{tabular}


59 The Influence of the critical factors on the behaviour......

\section{APPENDIX C}

Table 5.4 Composite Reliability Result

\begin{tabular}{|c|c|}
\hline Variable & Alpha Chronbach's \\
\hline$(\mathrm{X} 1)$ & 0.872 \\
\hline$(\mathrm{X} 2)$ & 0.879 \\
\hline$(\mathrm{X} 3)$ & 0.795 \\
\hline$(\mathrm{X} 4)$ & 0.959 \\
\hline$(\mathrm{X} 5)$ & 0.798 \\
\hline$(\mathrm{Y} 1)$ & 0.721 \\
\hline
\end{tabular}

Table 5.6 Testing Hypothesis

\begin{tabular}{|c|c|c|c|c|}
\hline & $\begin{array}{c}\text { Original } \\
\text { Sample (O) }\end{array}$ & $\begin{array}{c}\text { Sample Mean } \\
(\mathrm{M})\end{array}$ & $\begin{array}{c}\text { Standard } \\
\text { Deviation } \\
\text { (STDEV) }\end{array}$ & $\begin{array}{c}\text { T Statistics } \\
(\mid \mathrm{O} / \text { STDEV })\end{array}$ \\
\hline $\mathrm{X} 1$->Y1 & 0.08248 & 0.08635 & 0.01498 & 5.50639 \\
\hline $\mathrm{X} 2->\mathrm{Y} 1$ & -0.02742 & -0.03423 & 0.02862 & 0.95808 \\
\hline $\mathrm{X} 3->\mathrm{Y} 1$ & 0.10645 & 0.10877 & 0.02651 & 4.01518 \\
\hline $\mathrm{X} 4->\mathrm{Y} 1$ & 0.31563 & 0.32101 & 0.03298 & 9.56877 \\
\hline $\mathrm{X} 5->\mathrm{Y} 1$ & 0.59266 & 0.58781 & 0.03007 & 19.7040 \\
\hline
\end{tabular}

Table 5.7 Testing Result of Hypothesis and summary

\begin{tabular}{|c|c|c|}
\hline Hypothesises & Statements & Results \\
\hline H: 1 & $\begin{array}{l}\text { There is positive impact of Performance } \\
\text { Expectancy (PE) on Accountant } \\
\text { Behavior intention of using (CAS) }\end{array}$ & Supported \\
\hline H: 2 & $\begin{array}{l}\text { There is positive impact of Effort Expectancy (EE) } \\
\text { on Accountant Behavior intention of using (CAS) }\end{array}$ & Not Supported \\
\hline H: 3 & $\begin{array}{l}\text { There is positive impact of Task-technology fit } \\
\text { (TTF) on Accountant Behaviour intention of using } \\
\text { (CAS) }\end{array}$ & Supported \\
\hline H: 4 & $\begin{array}{l}\text { There is positive impact of Facilitating Conditions } \\
\text { (FC) on Accountant Behavior intention of using } \\
\text { (CAS) }\end{array}$ & Supported \\
\hline H: 5 & $\begin{array}{l}\text { There is positive impact of Self-Efficacy (S-E) on } \\
\text { Accountant Behaviour intention of using (CAS) }\end{array}$ & Supported \\
\hline
\end{tabular}




\section{APPENDIX D}

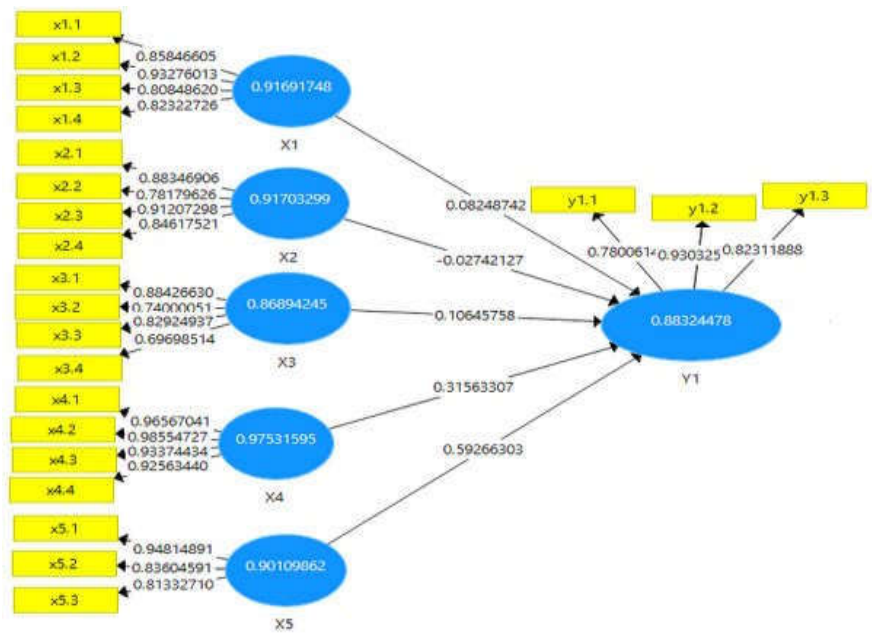

Figure 5.1. Conceptual Model The Impact Of Independent Variable To behavior intention of using CAS 